\title{
THE FEATURES OF MEDIATION IN EFL CLASSROOM INTERACTION: TEACHER PERSPECTIVES
}

\author{
Hanna Sundari \\ Department of English Education, Faculty of Language and Arts, Indraprasta PGRI University, Indonesia \\ E-mail: hanna.sundari@gmail.com; hanna.sundari@unindra.ac.id
}

APA Citation: Sundari, H. (2020). The features of mediation in EFL classroom interaction: Teacher perspectives. Indonesian EFL Journal, 6(1), 35-44. doi: 10.25134/ieflj.v6i1.2636.

Received: 01-09-2019

Accepted: 11-11-2019

Published: 01-01-2020

\begin{abstract}
The classroom is a place where the teacher, as an expert and the knower, teaches students through interactions influenced by several sociocultural backgrounds. Moreover, the teacher plays a role in mediating language learning processes by providing effective mediation. In brief, mediation can be defined as all objects delivered by the teacher to mediate the students to bring their current ability to the targeted performance. This current research serves to describe the features of mediation applied by English teacher in one lower secondary school in the EFL classroom context. This qualitative-based inquiry applied classroom observation and interviews as instruments to explore how the teacher mediated language learning in the classroom particularly for beginner-level students in one private school in Jakarta. The findings showed that the features of shared intention are the most salient to be mediated. This indicates that the teacher is very concerned with helping and facilitating the students to perform tasks. In addition, in mediating values, challenges, change and competence, the teacher creates engaging classroom discourses, selects particular tasks, and nurtures a positive classroom climate. Moreover, the teacher sets herself as a mediator as well as mediation as an ideal form of behavior and language model in the class.
\end{abstract}

Keywords: English; foreign language; mediation; sociocultural view.

\section{INTRODUCTION}

From the sociocultural view, learning is a social process and experience through social interactions in various settings. Moreover, for human, mental activity appears in the interaction with others in a certain experience (Lantolf, 2000). Then, Gredler (2009) also posits that social interactions with knowledgeable adults to scaffold the students beyond their capability are essential and significant. Particularly in language teaching, Lantolf (2000) in Atamturk, Atamturk and Dimililer (2018) asserts that it occurs in a social context in the social interaction with a more capable person. Through these interactions, the students develop both meanings and ways to make use of symbols to facilitate learning. Meanwhile, more competent adults play a role as "the ideal-form" of behavior which serves as a model for what the students should do in a particular developmental stage (Gredler, 2009). For example, parental language input/model provided by parents may guide the child in producing language and developing language complexity (Sundari, 2016a). In other words, the adults, parents or teachers help the students in controlling task elements, provide guidance to do the tasks, and assess the students' understanding.

The classroom setting is a place where a learning process between the students, as active receivers and the teacher as a more competent adult takes place through interactions. In the classroom, both parties, who are influenced by their status, identity and roles, create a small community with specific characteristics to attain the same learning goals. The language classroom, in this case, shows proofs of how language learning fundamentally occurs when the students actively and orally interact with each other for task completion. Moreover, in the language classroom, the oral interaction is not only facilitating learning, but also the source of both what the students learn and how they learn (Thoms, 2012). In general, Gredler (2009) argues that the teacher in the classroom becomes a model for appropriate behavior and provides guidance and assistance as the students work through the tasks as mediation. It can be stated that the teacher in the language classroom has to be a model of language for the students; at the same time, they help and lead them to enhance their language development through various types of mediation.

The concept of mediation in language learning was firstly offered by Vygotskian approach and Feuerstein's Theory of Mediation. The sociocultural theory views that the development of language ability is shaped in social interactions through participating in communicative practices 


\section{Hanna Sundari}

The features of mediation in EFL classroom interaction: Teacher perspectives

with guidance and assistance from a more competent participant (Thoms, 2012). The guidance and assistance then can be called mediation. Meanwhile, the one with the most knowledge, usually a parent, a teacher, or a peer is known as the mediator (Williams \& Burden, 2007). In mediated-learning experience, Feuerstein explains that visualizations, written explanation, models and examples are provided by mediators to stimulate the students to perform tasks (Poehner \& Infante, 2017). These put in mind, a mediation which is selected by the teacher in the classroom can be in various types and categories depending on several considerations, such as students' abilities, learning objectives, and targeted tasks.

In a very simple term, mediation can be referred to as the use of tools which are applied to solve a problem or achieve a goal (Williams \& Burden, 2007). The mediation can be in the form of the use of language or other sign symbols, such as charts, graphs, numbers, or objects; however, it is mostly delivered in linguistics and symbols so that guidance and assistance can be defined as mediation (Thoms, 2012). The function of mediation is to help the students move from the zone of incapability to that of ability to perform tasks. It is called Zone of Proximal Development (ZPD), which is "the difference between what a learner can do without help and what a learner can do with help" (Siyepu, 2013). In the language classroom, mediation, given by a more competent teacher or peer, leads the students in acquiring, experimenting and interacting language resources so that they can accomplish the tasks and promote language development. Moreover, Lantolf (2000) in Atamturk et al. (2018) states that language is a metaphorical tool of mediation and parents or teachers act as mediators to scaffold learning processes.

In mediated-learning experience, the cognitive and affective domains are inseparable in learning processes; as a result, Feuerstein (2003) cited by Poehner and Infante (2017) states that affective elements, such as feeling of competence and belief of positive behavior, might have implications on the students' orientation and performance. Therefore, in presenting a task, the teacher, as a mediator and a mediation herself, should select appropriate mediation that requires some criteria. Vygotsky believes that with proper assistance provided by the mediator teacher, a student at the ZPD can enhance the achievement to accomplish a particular task (Galloway, 2001) in (Siyepu, 2013). The key features of mediation proposed by Feuerstein (in Williams \& Burden, 2007) are displayed on Table 1.

Much of the research in second language learning and teaching is concerned with mediated processes particularly in the language classroom. The first and the foremost review is rendered by Lantolf (2000). He reviewed the research in second language learning as a mediated process for over 5 years and summarized that, as stated in the previous part, mediation can be in the form of social mediation, self-mediation, and artifact mediation which give implications to language learning and performance. Moreover, a study by Behroozizad, Nambiar and Amir (2012) taking six Iranian students found that scaffolding provided by the teacher mediates the English-asa-foreign-language (EFL) student's strategy development by reorganizing the classroom culture. Besides, the research carried out by Tulung (2013) in Indonesia gives a proof from the classroom that oral discourses generated through peer interactions using communicative tasks lead to the opportunities for second language (L2) production and decrease the use of L1. In addition, Kourieos and Evripidou's (2013) study of characteristics and teaching behaviors in Cyprus found that, based on students' perceptions, effective language teaching is seemingly connected to assumptions of a more assisting, mediating role of the language teacher instead of an authoritarian role of the said teacher.

Although a great deal of research has been conducted in the field of second/foreign language learning as a mediated process, some areas particularly in the foreign language setting are still uncovered. Many studies have been carried out in the ESL/EFL language setting in the university context while a few studies investigate contexts in which the students are beginner language learners in primary or secondary schools. Then, some works have been conducted in exploring classroom discourses and students' perceptions in the language classroom. However, only little research has been undertaken to discover teachers' perspectives about how they mediate language learning through interactions and why they finally select the types of mediation for the classroom. Indeed, the teacher, as a mediator in the language classroom, plays a significant role and authority in shaping the form of interactions and teaching as well as helping the beginner language students establish relationships, develop language skills and build a perception of what they experience. This may give implications and consequences to the process 
and result of language learning years after. To fill the research niche, this current study is to address the following research question: What features of mediation do the teacher apply in EFL classroom interactions at lower secondary school based on an Indonesian teacher's perspective?

Table 1. The key features of mediation by feuerstein (Williams \& Burden, 2007)

Features of Mediation Descriptions

\begin{tabular}{ll}
\hline Significance & Aware of the significance of the learning task \\
Purpose beyond here and now & Aware of wider relevance beyond immediate time and place \\
Shared intention & A clear intention (understood and reciprocated by the students) \\
A sense of competence & Feeling of being successful in doing particular tasks \\
Control of behavior & Regulating learning, thinking and action \\
Goal-setting & Setting realistic goals and ways to achieve them \\
Challenge & Providing suitable challenge to the students' current capabilities \\
Awareness of change & Recognizing changes \\
A belief in positive behavior & The possibility in finding solutions \\
Sharing & Solving problems cooperatively \\
Individuality & Recognizing own individuality and uniqueness \\
A sense of belonging & Belonging to a community and culture \\
\hline
\end{tabular}

\section{METHOD}

As a part of inquiry into language classroom interactions, this current research is qualitativebased. In qualitative research, one of the characteristics is to empower participants to share their voices under the participants' contexts/settings using some instruments to induce and establish patterns and themes to address a problem or issue (Creswell, 2007). This current study is aimed at exploring the features of mediation applied by English teacher in EFL learning environment.

The research site was one private junior high school in Jakarta, the capital of Indonesia. The participant of the research was one English language teacher whose name was Yanti (a pseudonym). She was special since she had unique and interesting teaching experience. From the initial classroom observation, Yanti employed very attractive and engaging classroom activities when building interactions with the students. Yanti has been teaching English at lower secondary schools for more than 17 years in four different schools, both public and private schools, including the one in which this research took place. Despite the fact that she was graduated from a non-education major, Yanti had a high passion in teaching and decided to improve her professional teaching qualifications by taking a master's degree program in education. Moreover, she also becomes one of teacher trainers in her current institution she works for. The teaching experience, dedication, and career development make her appropriate to be recruited as participant.

To collect the data, the instruments used were classroom observation/recordings and interviews.
Classroom observation/recordings were taken 5 times in approximately 3 hours 40 minutes for identifying the features of mediation applied by the teacher in classrooms for grade 7. Moreover, the interview lasted for approximately 80 minutes in exploring deeper understanding about the features applied based on the teacher's perspectives, ideas, and thoughts. The interview was then transcribed verbatim. The data from both observation and interviews were analyzed following the steps in open coding and developing themes. After that, the emerging themes were classified and discussed from the view of key features of mediation by Feuerstein (Williams \& Burden, 2007).

\section{RESULTS AND DISCUSSION}

From the collected data, not all features of mediation clearly came into view when the participant teacher, Yanti, mediated language learning through interactions in the classroom. However, it was revealed that the feature of shared intention in which classroom strategies built by students' understanding of what the activity was all about and how they had to do it was the most frequently applied and emerged in the classroom. The data were then presented based on the three main features of mediation: significance, purpose beyond here and now, and shared intention. After that, the other features were also described and discussed.

In general, it could be seen that the features of the mediation in language learning could be mediated by everything that played a role in either providing language resources or simulating the use of the target language. In the classroom, the participant teacher and the students mostly 


\section{Hanna Sundari}

The features of mediation in EFL classroom interaction: Teacher perspectives

had an asymmetrical relation; this went exactly as reported by Consolo's (2006) study. Therefore, the teacher, Yanti, as the more competent, knowledgeable participant, had the authority to manage classroom activities and control the students' activities particularly in English in the foreign language classroom with especially beginner-level students at the secondary school. All objects in the class could be used as mediation, including the teacher herself as the main mediation by using language and symbols in interactions and communication. As Gredler (2009) points out, the teacher serves as an ideal model to appropriate behavior and provides guidance when the students perform the tasks.

Possessing seventeen years of experience in teaching English at lower secondary schools, Yanti, of course, has faced a great number of students in many classes from different cultures and backgrounds. Despite the fact that she did not take the education major, she pursues a professional career in teaching and now attends her master's degree program in the English education major. Having taught a lot of classes, she finally concludes that her major teaching goal in lower secondary schools $(S M P)$ is to change the image or give a positive impression of the English subject among students. From the interview, she asserted that "They have just known English since attending SMP (lower secondary school). At that time, they did not like it. So, I have to change it. English is fun; English is something worth learning. My current passion in teaching is to make them love English... at least they love $m e$ ". By delivering fun English, she expects that the students will love it. At least, they turn to want to study it because of her. In short, she, as a teacher, posits herself as the mediation as well as the mediator to bridge the students and the subject because the teacher and the subject taught are inseparable being in one package. Besides the fact that the teacher needs to have knowledge, pedagogical and communicative competences, good personality traits, such as being helpful, friendly, humorous and attentive, which all make the students love the teacher are also prominent characteristics of effective language teachers (Nghia, 2015; Shishavan \& Sadeghi, 2009; Sundari, 2016b; Wichadee, 2010).

Though the participant teacher did not explicitly share and verbally convey to the students what the significance of any given activity was, it was clearly seen that she carefully selected a particular activity which was not only to enhance language proficiency, but also to build characters in the students. For instance, she set class rules at the first meeting, such as saying please to show politeness and using Islamic expressions such as excellent, alhamdullilah to show the Islamic values as required by the school system. Moreover, in mediating, she also tried to help the students perceive the values by giving clear direction, repetition, elicitation. Those practices depicted the key features of significance in mediation.

Concerned with the students, Yanti, the participant teacher, highly realized what she worked on. She really noticed who the students were, what class she entered and how she dealt with them. She thought that every student was unique. She believed that language is like "a recording" that needs a lot of exposure. Learning language is not just memorizing a set of rules and imitating sound patterns; moreover, the students need to experience and use the language in various types of communication with the teacher and/or others. Therefore, the purpose of language learning is not only to perform given tasks inside the classroom, but also to get competences leading them to better language performance in the next grade. Not only having a very clear view about language learning, she also revealed that adjustment in teaching methods and learning styles was frequent in planning and lessons. For example, when handling classes with kinesthetic students, she prepared some games that required the students to move around. Meanwhile, a set of songs was also made ready as an attention getter for passive auditory students. Experiencing the language that leads to meaningful learning by making adjustment of teaching methods and setting several opening activities can be pointed out as one feature of purpose beyond here and now (Table 2).

Table 2. Features of purpose beyond here and now

1. Making Adjustment of teaching methods to the students' learning styles

2. Experiencing the language, not only miming

3. Setting several opening activities

4. Creating meaningful learning

The shared intention was the most salient From the classroom observation, there could be feature in mediating language learning (Table 3). listed some strategies applied by the participant 
teacher in describing precisely what she wanted the students to do and ensuring that the students understood exactly what was required of them to do. Using tools, such as audio-recordings, movies, and songs were alternative features to sharpen the purpose and perception. She uttered that she modeled several samples of greeting cards before asking them to make one. By giving a lot of exposure, she expected that the students could comprehend, modify, and produce language related to a required task, namely, making greeting cards as a sample using their own ideas and language resources. Moreover, slow pace, confirmation, repetition, and the use of L1 were chosen to make sure that the students understood what to do in the given task and had the willingness and ability to do it. Slow pace as a characteristics of teacher talk is also found in studies by Rashidi and_Rafieerad (2010), Sundari (2017) and Walsh (2011). Then, the use of L1 as a medium of instruction for beginner language students is also similar to Harmer's view (2007) and research reported by Petek (2013) and Sundari (2017).

Table 3. Features of shared intention

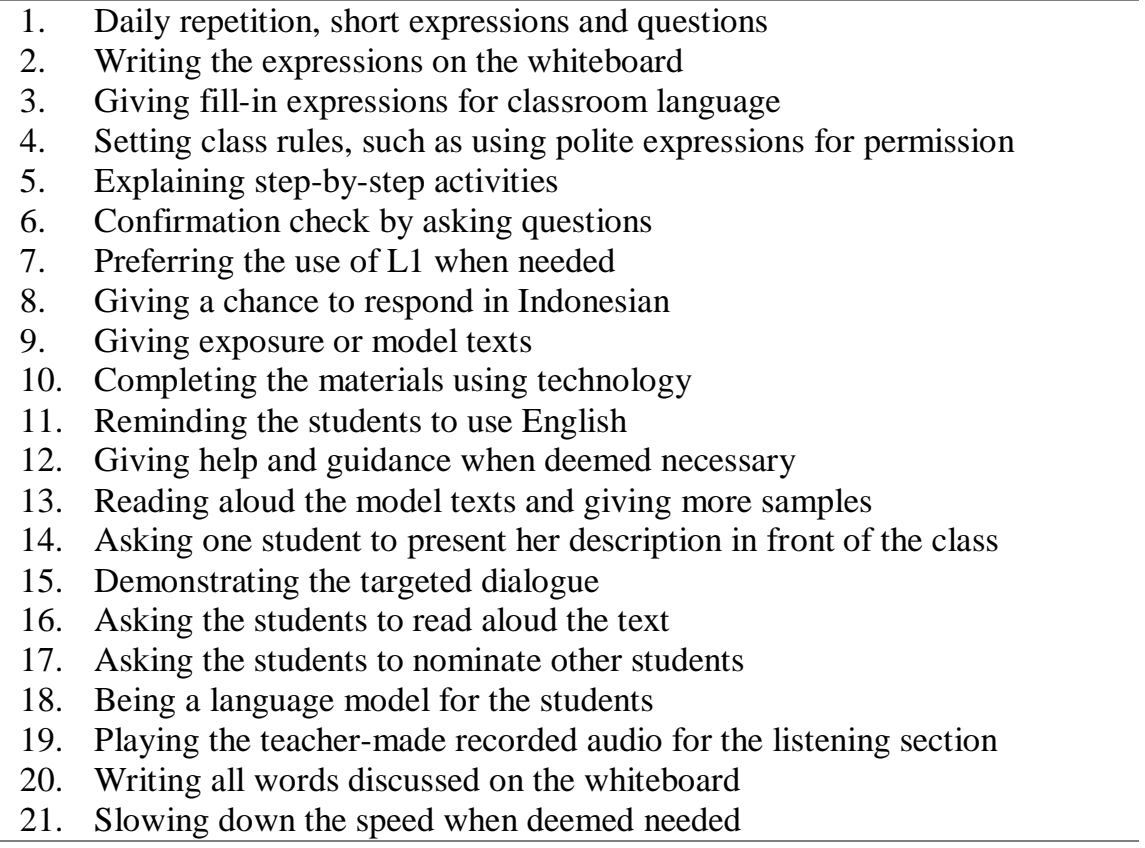

In line with the major goal of her teaching, the participant teacher created a fun and enjoyable classroom climate to encourage the students' positive self-image. She revealed that she tried to give feedback proportionally by avoiding facethreatening acts for the students. Fostering them to express themselves in English, even though it was wrong, with no fear of failure or being blamed mediated the learning to make the students gain confidence in using the language and feel competent. In mediating the sense of competence, proportional feedback, chance to use the language, humor and praise as the features of mediation could enhance the feeling of confidence and competence (Table 4).

Not only facilitating a positive climate for the students to feel competent in doing the tasks, the participant teacher also mediated challenge in the class to improve the students' language use through leveling questions and tasks and giving rewards. The participant teacher said that the questions were gradually delivered depending on the students' excellence. The more excellent the students turned, the more complex the questions became. For grade nine, she thought that the students were quite ready for logical, analytical questions. Moreover, she also said that she had already prepared a list of questions for various activities. Sometimes, several questions were for a similar purpose in a case where the students did not understand them in the first place. For instance, she modified her questions: What should you do after this? What do you have to do? Or After this, you have to do what? Number one? Two? Giving repeated questions is also found in a study by Rido (2017); he states that teachers delivered questions repeatedly when there was no response or when they were not sure that the students understood the question. To give a feeling of challenge, once she set a group competition in the form of a whispering-horse activity for the listening and speaking sections 


\title{
Hanna Sundari
}

The features of mediation in EFL classroom interaction: Teacher perspectives

with hobbies as the topic. In another activity, the students were asked to write down their answers on the whiteboard; then she announced the best students of the day and gave them rewards. The participant teacher mediated challenge in the language learning through leveling questions and tasks, competitions, and rewards (table 5).

Table 4. Features of sense of competence

1. Class feedback (evaluation) or personal feedback

2. Not focusing on grammar rules

3. Lecturing no more

4. Giving praise or appreciation

5. Chance to use the language though wrong

6. Room for humor

7. Calling the students' names with fairness

8. Extending the time

9. Facilitating the students' requests

The participant teacher then mediated change by mapping the students' abilities and giving monitor and assessment (table 6). She said that she gave a simple written test as a placement test at the first years of teaching to decide what kind of treatment she had to give. Different classes needed different treatment, she said. Over the time, with more experience to handle classes, she just opened a conversation with the students for the ice-breaking purposes at the first meeting. After that, the treatment for the class was decided. Meanwhile, during the class activity, when the students performed the given task or did language exercises in pairs or in groups, she moved around the class to monitor and give feedback and help when deemed needed. She gave correction or remedy to all students' answers either on the whiteboard or in the books. She also provided some praise for several outstanding performances. Therefore, she mediated the change of students' performance by giving oral and written tasks, such as completion and reading tests and evaluating how well the students could accomplish them. How feedback is effective in learning processes and outcome is also reported by Behroozizad, Nambiar and Amir (2012). They sum up that in general, teacher feedback connects the students, self-confidence and the use of language particularly for listening-speaking tasks.

Table 5. Features of challenge

\author{
1. Levels of questions \\ 2. Levels of task difficulty such as leveling worksheets \\ 3. Announcing the best students of the day \\ 4. Giving rewards
}

The participant teacher then mediated change by mapping the students' abilities and giving monitor and assessment (Table 6). She said that she gave a simple written test as a placement test at the first years of teaching to decide what kind of treatment she had to give. Different classes needed different treatment, she said. Over the time, with more experience to handle classes, she just opened a conversation with the students for the ice-breaking purposes at the first meeting. After that, the treatment for the class was decided. Meanwhile, during the class activity, when the students performed the given task or did language exercises in pairs or in groups, she moved around the class to monitor and give feedback and help when deemed needed. She gave correction or remedy to all students' answers either on the whiteboard or in the books. She also provided some praise for several outstanding performances. Therefore, she mediated the change of students' performance by giving oral and written tasks, such as completion and reading tests and evaluating how well the students could accomplish them. How feedback is effective in learning processes and outcome is also reported by Behroozizad, Nambiar and Amir (2012). They sum up that in general teacher feedback connects the students, self-confidence and the use of language particularly for listening-speaking tasks.

Table 6. Features of awareness of change

1. Mapping the students' abilities

2. Providing different activities for different classes

3. Assessing the students' performance 


\section{Monitoring the students one by one by moving around the class}

Furthermore, the participant teacher mediated the feature of sharing by setting class activities in the mode of small groups, pair groups and individual activities. She said that the language proficiency and types of activity became consideration in setting the class mode. The class with excellent students tended to actively do all the required tasks both individually and in small groups, while the low-achieving students were more dependent and non-autonomous. This view is quite similar to what Harmer (2007) asserts that individual activities foster autonomy and independence while pair and group work facilitate the use of language with peers. Then, the participant teacher finally preferred three to four students in one group that she considered to be quite effective for a language class. The lower level the students were, the smaller the group setting had to be, she concluded. Classroom modes in the combination of individuals, pair and group activities are also reported by Behroozizad, Nambiar and Amir (2012), Nisa (2014), and Sundari, Rafli and Ridwan (2017).

In mediating individuality, particularly for grade nine as the highest grade in $S M P$, the participant teacher stated that she gave opportunities to the students to express their personal ideas and individual choices. Meanwhile, for the lower grades, exposure by giving a lot of samples or model texts from the teacher was emphasized to enrich the students' language repertoire. From the classroom observation/recording, the participant teacher provided tasks for each meeting in each class to accomplish particular learning objectives. Using one task activity for each meeting, she could mediate, though not always, several areas of mediation features.

Table 7. Samples of task activities and features of mediation

Task Activities
Task Activity 1
Using a worksheet, each student has to
ask two classmates, who sit on the
opposite and diagonal sides, about their
hobbies based on a set of pictures on the
sheet. Then, they present the result
orally.

Task Activity 2

The class is divided into groups of five by asking them to count to five. Each similar number combines together to make one group to play a whisperinghorse game. Each student whispers a friend's hobbies and hers to the student next to her. Then, the last student in the group writes all the answers on the whiteboard.

Task Activity 3

Using a worksheet, the students are assigned to write things in the classroom and rooms at the school in the provided table. Then, the teacher plays the teacher-made recording audio about the same topic and asks the students to fill in the blanks in the text based on the description they hear.
In the language learning view, the purpose of the task is to learn Simple Present Tense in expressing hobbies particularly for speaking and listening skills. However, at another phase, it has a value to get better understanding and use of the language in real communication. The teacher mediates individuality for the students to have ample room to show their own choices with no feeling of incompetence. Reflection given by the teacher when asking "what have we learned today? mediates the awareness of change that the students make in their language development, in this case expressing hobbies using Simple Present Tense. Setting the class in a mode that leads them to communicate to others, the teacher mediates sharing when they help each other to solve a problem.

This task focuses on speaking and writing skills, and the topic is expressing hobbies using Simple Present Tense. By selecting an appropriate task that fits on the grid, the teacher makes the students feel successful, mediating a sense of competence. To mediate challenge and change, the teacher evaluates the answers, gives correction when deemed needed, and provides rewards to the group with the best performance.

Though this kind of activity sounds common in the listening section, it also brings the value of students' building vocabulary and using language resources. Initiating the activity with a discussion can mediate sharing by constructing behavior such as listening attentively, taking turns, checking and cooperating. 


\section{Hanna Sundari}

The features of mediation in EFL classroom interaction: Teacher perspectives

Based on the findings, by selecting one particular task activity and selective classroom discourse in building interactions, the participant teacher mediated some areas of mediation. The task activities and the classroom discourses delivered by the teacher could mediate the value of the lesson, give the students the opportunity to use the language through interactions, and enhance their language capability without feeling incompetence. Furthermore, the classroom climate created by the teacher drove the students to enjoy and get involved in the task activities. In line with Vygotsky's sociocultural view (Gredler, 2009), it can be concluded that the participant teacher has effectively accomplished her role as the ideal-form of behavior and a language model for the students. The teacher provided assistance by fulfilling the students' needs and creating an effective classroom context (Atamturk et al., 2018). In addition, the participant teacher has effectively become a mediation and a mediator to mediate some features of mediation in presenting the lesson by providing fruitful task activities in the classroom interaction. These findings are also consistent with what is stated by Atkinson, Derry, Renkl and Wortham (2000) in Siyepu (2013) that learning environment is the most effective when a dynamic interaction between the teacher, students, and task brings plenty of room for the students to create understanding during interactions.

\section{CONCLUSION}

Constructed with the Sociocultural Theory and Mediation Theory by Feuerstein in mind, this paper is aimed at describing the features of mediation applied by English language teachers in lower secondary schools in the EFL learning environment. The findings show that the participant teacher mostly mediates the features of purpose and shared intention by selecting tasks, using teaching media and manipulating classroom discourses, such as talk, questions, intonation and pace, and demonstration. Moreover, in mediating challenge and change, she applies some leveled tasks and questions, gives praise and rewards, and monitors assessment to evaluate how the students could climb up the stairs of knowledge and performance. In addition, having good personality traits as a teacher, she succeeds particularly in dealing with beginner language students at lower secondary schools. She plays her role as an ideal form of behavior and language model as well as encourages the students to feel the success of doing the tasks without feeling of failure or incompetence by creating a fun classroom climate. Experience in attending many classes and handling various kinds of students leads her to know exactly what the students need in learning the language and how they can fulfill the needs.

This research does not address the evaluation of how effective the teacher mediates language learning in the classroom interaction, nor does it assess the success in the teacher's teaching process. However, especially with beginner-level students in the EFL context in mind, these research findings have proven that the more knowledgeable, experienced participant, namely, the teacher in this case, plays a significant role in mediating the students to meet the learning objectives and accomplish the tasks as well as facilitate their language development

\section{REFRENCES}

Atamturk, N., Atamturk, H., \& Dimililer, C. (2018). Native speaker dichotomy: Stakeholders' preferences and perceptions of native and nonnative speaking English language teachers. South African Journal of Education, 38(1), 1-10.

Behroozizad, S., Nambiar, R. M. K., \& Amir, Z. (2012). The relationship between language learning strategies and teacher' s mediating role. 3L: The Southeast Asian Journal of English Language Studies, 18(2), 35-48.

Consolo, D. A. (2006). Classroom oral interaction in foreign language lessons and implications for teacher development. Linguagem \& Ensino, 9(2), 33-55.

Creswell, J. W. (2007). Qualitative inquiry \& research design: Choosing among five approaches $\left(2^{\text {nd }}\right.$ ed.). doi: 10.1016/j.aenj.2008.02.005.

Gredler, M. (2009). Learning and instruction: Theory into practice. New Jersey: Pearson Education, Inc.

Harmer, J. (2007). The practice of English language learning. Malaysia: Pearson Education Limited.

Kourieos, S., \& Evripidou, D. (2013). Students' perceptions of effective EFL teachers in university settings in Cyprus. English Language Teaching, 6(11), 1-16. doi: 10.5539/elt.v6n11p1.

Lantolf, J. P. (2000). Second language learning as a mediated process. Language Teaching, 33(2), 79-96. doi: 10.1017/S0261444800015329.

Nghia, T. L. H. (2015). Vietnamese students' perception of English teacher qualities: Implications for teacher professional development. International Journal of Academic Research in Education and Review, 3(1), 7-19. doi: 10.14662/IJARER2014.058.

Nisa, S. H. (2014). Classroom interaction analysis in Indonesian EFL speaking class. English Review: Journal of English Education, 2(2), 124-132. 
Petek, E. (2013). Teacher's beliefs about classroom interaction and their actual practices: A qualitative case study of a native and a nonnative English teacher's in-class applications. Procedia - Social and Behavioral Sciences, 70, 1195-1199. doi: 10.1016/j.sbspro.2013.01.176.

Poehner, M. E., \& Infante, P. (2017). Mediated development: A Vygotskian approach to transforming second language learner abilities. TESOL Quarterly, 51(2), 332-357. doi: 10.1002/tesq.308.

Rashidi, N., \& Rafieerad, M. (2010). Analyzing patterns of classroom interaction in EFL classrooms in Iran. Journal of Asia TEFL, 7(3), 93-120.

Rido, A. (2017). Questioning strategies of master teachers in Indonesian vocational English classrooms. TEFLIN Journal, 2(28), 193-211.

Shishavan, B. H., \& Sadeghi, K. (2009). Characteristics of an effective English language teacher as perceived by Iranian teachers and learners of English. English Language Teaching, 2(4), 130-143. doi: 10.1017/CBO9781107415324.004.

Siyepu, S. (2013). The zone of proximal development in the learning of mathematics. South African Journal of Education, 33(2), 1-13.

Sundari, H. (2016a). Pengaruh input bahasa orangtua terhadap kompleksitas bahasa anak: Studi kasus pada anak usia 5 tahun melalui interactive shared reading. Jurnal Pendidikan Bahasa Dan Sastra, 16(April), 110-121.

Sundari, H. (2016b). The qualities of an effective English teacher: University students' perception. In R. Paul \& J. Adamson (Eds.), TESOL
https://journal.uniku.ac.id/index.php/IEFLJ/index

Indonesia International Conference Edition: Teaching \& Learning English in Indonesia Future Trends and Approaches, 2, 205-209. Lombok Indonesia: The English Language Education Publishing.

Sundari, H. (2017). Classroom interaction in teaching English as foreign language at lower secondary schools in Indonesia. Advances in Language and Literary Studies, 8(6), 147-154.

Sundari, H., Rafli, Z., \& Ridwan, S. (2017). Interaction patterns in English as foreign language classroom at lower secondary schools. English Review: Journal of English Education, 6(1). doi: 10.25134/erjee.v6i1.775.

Thoms, J. J. (2012). Classroom Discourse in foreign language classrooms: A review of the literature. Foreign Language Annals, 45(S1), 8-27. doi: 10.111/j.1944-9720.2012.01177.x.FOREIGN.

Tulung, G. J. (2013). Oral discourse generated through peer-interaction while completing communicative tasks in an EFL classroom. TEFLIN Journal, 24(2), 220-236. doi: 10.15639/TEFLINJOURNAL.V24I2/220-236.

Walsh, S. (2011). Exploring classroom discourse: Language in action. Oxon: Routlege Taylor \& Francis Group.

Wichadee, S. (2010). Defining the effective English language teacher: Students' and teachers' perspectives. JALT2009 Conference Proceedings, 27-35.

Williams, M., \& Burden, R. L. (2007). Psychology for language teachers: A social constructivist approach. Cambridge: Cambridge University Press. 
Hanna Sundari

The features of mediation in EFL classroom interaction: Teacher perspectives 